\title{
$\boldsymbol{H}_{2} / \boldsymbol{H}_{\infty}$ 설계사양을 만족하는 선박운동제어계 설계에 관한 연구
}

\section{Control System Design for Marine Vessel Satisfying Mixed $\boldsymbol{H}_{2} / \mathrm{H}_{\infty}$ Performance Condition}

\author{
강 창 남, 김 영 복* \\ (Chang-Nam Kang ${ }^{1}$ and Young-Bok Kim²) \\ ${ }^{1}$ Faculty of Mechanical System Engineering, Jeju National University \\ ${ }^{2}$ Department of Mechanical System Engineering, Pukyong National University
}

\begin{abstract}
In this paper, the authors propose a new approach to control problem of the marine vessels which are moored or controlled by actuators. The vessel control problem in the specified area is called a DPS (Dynamic Positioning System). The main objective of this paper is to obtain more useful control design method for DPS. In this problem, a complicate fact is control allocation which is a numerical method for distributing the control signal to the controlled system. For this, many results have been given and verified by other researchers using two individual processes. It means that the controller design and control allocation design process are carried out individually. In this paper, the authors give more sophisticated design solution on this issue. In which the controller design and control allocation problem are unified by a robust controller design problem. In other word, the stability of the closed-loop system, control performance and allocation problem are unified by an LMI (Linear Matrix Inequality) constraint based on $H_{2} / H_{\infty}$ mixed design framework. The usefulness of proposed approach is verified by simulation with a supply vessel model and found works well.
\end{abstract}

Keywords: dynamic positioning system, marine vessel, control allocation, robust control, stability, control performance, linear matrix inequality

\section{I. 서론}

항공기를 포함하여 해상·해저에서 운용되는 선박 및 잠 수정은 다수의 액추에이터에 의해 운동이 제어된다. 운동제 어를 위해 운동체에 설치되는 액추에이터는 이론적인 관점 에서 보다 기술적으로 수월하게 운동체를 제어하기 위한 관점에서 그 수를 결정하는 것이 일반적이다. 이때 액추에 이터 수의 적고 많음은 운용면에서는 큰 문제가 없으나 제 어계설계문제, 즉 제어이론적인 관점에서는 다소 간의 어려 움을 유발시키기도 한다. 구체적으로는 제어입력수와 제어 변수가 다른 경우가 이 문제에 해당된다. 즉, 예를 들어 수 상운동체의 경우 제어변수는 서지(surge), 스웨이(sway), 요 우 각(yaw angle) 3개이다. 이러한 3가지 운동을 직접적으로 제어하기 위해서는 결국 3 개 이상의 액추에이터가 필요하 며 그렇게 설치하고 운용하는 것이 일반적이다. 바지선 (Barge Ship), Rigs, FPSO 및 드릴쉽(Drill Ship) 등에는 4기 이상의 액추에이터(윈치 및 추진장치)가 설치 운용되기도

\footnotetext{
* 책임저자(Corresponding Author)

Manuscript received March 11, 2013 / revised May 21, 2013 / accepted July 10, 2013

강창남: 제주대학교 기계시스템공학부(kangcn@jejunu.ac.kr)

김영복: 부경대학교 기계시스템공학과(kpjiwoo@pknu.ac.kr)

※ 본 논문은 2013년도 정부(교육과학기술부)의 재원으로 한국연구 재단의 기초연구사업 지원을 받아 수행된 것임(2012R1A1A 2039012). 또한 2013년도 해양수산부의 재원으로 한국해양과학 기술진흥원의 지원을 받아 수행되었음(해양플랜트 거주용 부선 의 계류위치제어시스템 개발).
}

한다. 반면 수중운동체의 경우에는 6 개의 제어변수 6 자유도 운동)가 주어지며 필요에 따라 6 개 이하 혹은 그 이상의 적절한 수의 액추에이터를 설치하여 운용한다. 제어계를 설 계하는 측면에서는 제어변수와 제어입력수가 일치하는 것 이 가장 부담이 적으며 이러한 조건이 가장 일반적이다. 그 러나 앞서 기술한 수상 및 수중운동체 제어문제의 경우에 는 그 일반적인 사실이 통용되지 않는 것이 사실이다. 이것 을 산술적인 방법으로 해결하고자 하는 것이 제어력 분배 법(control allocation)이다. 즉, 제어변수가 3개이고 액추에이 터가 4개이면 제어대상을 제어하기 위해서는 제어신호를 4 기의 액추에이터로 분배하면 된다. 그래서 액추에이터 수에 대응하여 제어기에서 계산된 제어신호를 효과적으로 분배 하는 것이 제어력 분배법의 최종목표가 된다.

제어력 분배에 대한 연구는 오래전부터 수행되어 왔고, 다양한 연구결과가 보고되고 있다[1-7]. 이와 관련한 최근 연구 중 그 대표적인 것이 Fossen 등의 연구결과이다[3-6].

기존 연구에서는 먼저 제어기를 설계한 후 완전히 독립 적으로 제어력을 분배하기 위한 전달행렬을 구하는 방법을 제안하고 있다. 즉, 제어력 분배에 따른 제어계의 안정성과 제어성능 등의 문제에 대해서는 고려하지 않고 있다.

본 논문에서는 기존 연구결과와는 달리, 제어력 분배 및 제어계 안정성 등을 동시에 고려하여 제어기를 설계하는 문제에 대해 고찰한다. 즉, 제어력 분배를 포함한 제어기 설계문제를 강인제어기법에 기초한 제어기 설계문제로 변 환하고 특히, $H_{2} / H_{\infty}$ 제어성능을 만족하도록 하는 제어기를 
설계하도록 한다. 동시에 제어대상의 파라미터가 변하는 경 우를 고려하여 파라미터 변동에도 제어계의 안정성이 보장 되도록 한다. 즉, 변동하는 파라미터는 복수이고 그것이 일 정범위에서 변하는 경우에도 제어계의 안정성과 제어성능 이 보장되도록 하는 제어기를 LMI (Linear Matrix Inequality) 기법을 이용하여 설계한다. 최종적으로 설계된 제어계의 강인성과 제어성능을 시뮬레이션을 통해 평가하 고 그 유효성을 검증한다.

\section{II. 문제설정}

선박운동제어를 위한 제어계 설계과정에서 다소 번거로 운 과정 중의 하나가 제어력 분배 문제이다. 이것은 제어대 상 선박에 설치되어 있는 추진장치 수와 직접적으로 관련 된다. 서론에 기술한 것과 같이 3 개의 운동을 제어하는 경 우에는 제어기로부터 생산되는 3 개의 제어신호를 4 개 혹은 그 이상의 액추에이터로 적절히 분배하여야 한다. 제어력 분배효과를 극대화하기 위해서는 제어신호를 적절히 분배 해야 할 뿐만 아니라 액추에이터를 적절히 배치하는 문제 까지 고려해야 하는 통합적인 문제로 다루어야 한다.

이와 같이 제어력 분배는 통합적인 관점에서 다루어야 할 상당히 복합적인 문제의 하나로 봐야 한다. 따라서 본 논문에서는 제어기를 설계하고 제어기로부터 생산된 제어 신호를 액추에이터에 단순히 전달하는 개념에서 벗어나, 전 체 제어계의 안정성 및 제어성능을 동시에 고려하는 문제 를 다룬다.

제어력 분배 문제는 이미 Sordalen 등 많은 연구자에 의 해 이론적인 결과가 도출되어 있다[1-6]. 특히 최근에는 수 상 및 수중운동체를 대상으로 Fossen 등[3-6]이 기존연구결 과의 적용 및 확장된 연구결과를 보고하였으나 이 결과 역 시 통합적인 관점에서 다루어야 할 중요한 문제(제어계 안 정성 및 제어성능)를 간과하고 있다.

본 연구에서는 제어대상을 수상운동체로 설정하고 Fossen 등[3,4]의 연구결과를 기본으로 하여 제어력 분배 문 제에 대한 새로운 접근법과 제어기설계법을 제안한다. 즉, 제어기설계와 제어력 분배 문제를 하나의 일관된 과정을 거쳐 완성하는 통합적인 방법에 대해 고찰한다. 기본적으로 는 강인제어기법에 기초하여 제어력을 최적으로 분배하면 서 안정성과 제어성능이 보장되도록 하는 새로운 기법을 제안한다. 제어대상으로는 스러스트, 터그보트 및 무어링윈 치에 의해 제어되는 바지선 및 수상선을 고려한다. 즉, 좌. 우 두기씩 대칭적으로 4 기의 액추에이터가 설치되어 있다 고 가정한다.

먼저, 그림 1 은 가장 기본적인 제어력 분배 문제를 나타 내고 있는데 여기서 $\tau_{c}$ 는 제어기로부터 발생되는 제어신호 이고, 서지, 스웨이 방향 힘 및 요우 모멘트 운동을 억제시 키는 제어력이다. 이것은 다시 선박에 설치된 4 기의 액추에 이터(윈치 혹은 스러스트)에 전달된다.

제어기로부터 제어신호가 생성되어 제어력 분배법에 의 해 각 액추에이터에 전달되게 되는 신호는 각 액추에이터 가 발생시켜야 할 힘, 액추에이터와 제어대상 선박이 이루 는 각도 $\left(\boldsymbol{f}_{i}, \alpha_{i} ; i=1, \ldots, 4\right)$ 등이 된다.

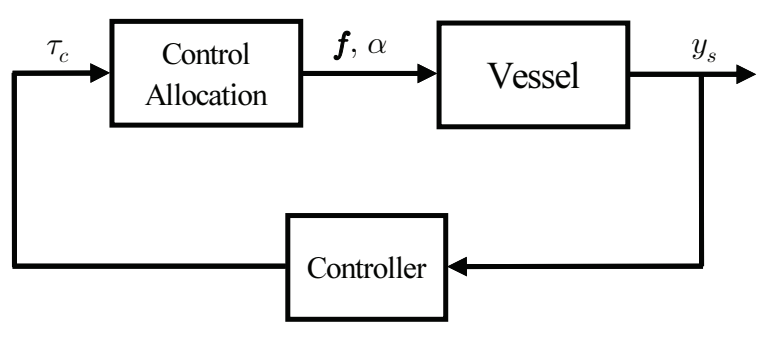

그림 1 . 제어력 분배 문제 기본 개념.

Fig. 1. Basic concept of control allocation.

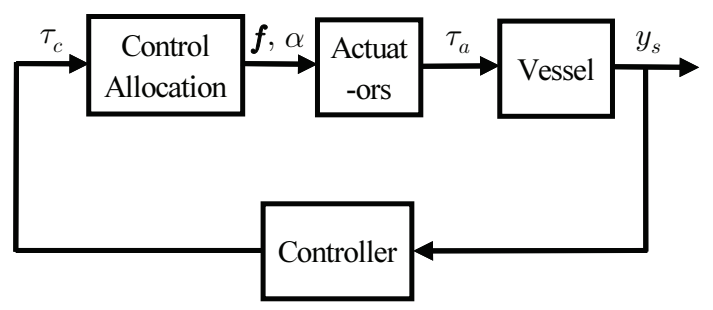

그림 2. 액추에이터를 포함한 확장된 제어력 분배 문제.

Fig. 2. An extended control allocation problem with actuators.

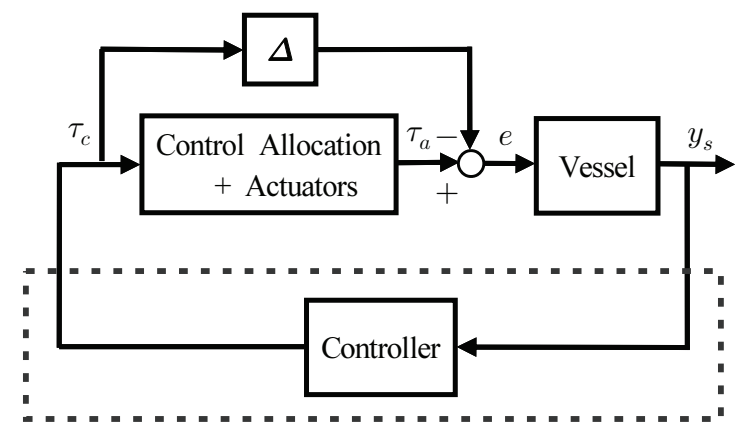

그림 3. 강인제어기법에 기초하여 확장된 제어력 분배 문제.

Fig. 3. Extended control allocation problem based on robust control.

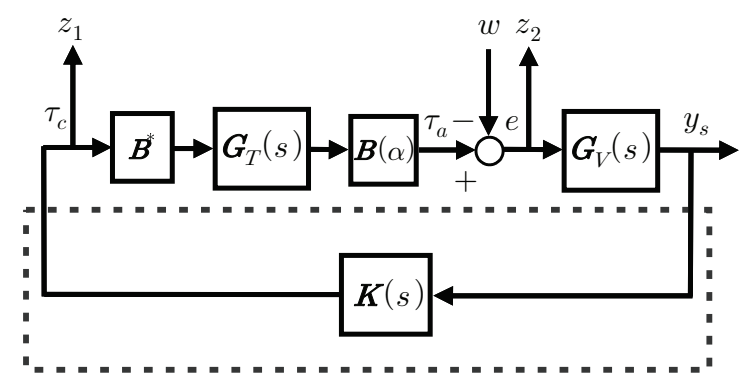

그림 4. $H_{\infty}$ 제어기법에 기초한 제어력 분배 문제의 표현.

Fig. 4. Control system description based on $H_{\infty}$ control framework.

이때 제어기 설계와 제어력 분배 문제를 동시에 다루기 위해 우선 그림 2 와 같이 선박과 액추에이터를 독립적으로 각각 분리하여 나타낸다.

제어력 분배 문제는 제어기로부터 계산된 신호 $\tau_{c}$ 와 스 러스트 등의 보조추진장치로부터 만들어지는 제어신호 $\tau_{a}$ 
와의 차이를 가능한 줄이는 것이 가장 기본적인 목표이다.

이미 기술한 것과 같이 수식적으로는 $\left\|\tau_{c}-\tau_{a}\left(\boldsymbol{f}_{\boldsymbol{i}}, \alpha_{i}\right)\right\|$ $<\gamma(>0)$ 와 같이 그 설계지표를 설정할 수 있다[1-6]. 이 러한 설계지표를 참고로 하면, 강인제어기법에 따라 그림 3 및 그림 4과 같이 제어력 분배 문제를 재설정할 수 있게 된다. 이 표현에 따라 강인제어기법을 이용하여 제어력 분 배와 제어기설계문제를 동시에 해결하도록 한다.

\section{III. $H_{2} / H_{\infty}$ 설계사양을 만족하는 제어계 설계}

본 논문에서 고려하는 수상선박은 선체 중심선을 기준으 로 서로 대칭이고 무게 및 회전중심도 좌표중심 근처에 있 다고 가정한다. 그리고 선박운동방정식을 다음과 같은 선형 모델로 나타낸다[4].

$$
\begin{aligned}
& M \dot{\nu}+D \nu=\tau \\
& \dot{\eta}=R(\varphi) \nu
\end{aligned}
$$

여기서 $\boldsymbol{M} \in R^{3 \times 3}$ 은 관성행렬이고, $\boldsymbol{D} \in R^{3 \times 3}$ 는 댐핑행 렬로 각각 식 (2)와 같이 표현되며, $\boldsymbol{\eta}=[x, y, \varphi]^{T} \in R^{3 \text { 는 }}$ 지구고정좌표(Earth Fixed Frame)에서의 위치 $(x, y)$ 와 각 도 $\varphi$ 에 대한 관성위치이다.

$$
\begin{aligned}
\boldsymbol{M} & =\left[\begin{array}{ccc}
m-X_{\dot{u}} & 0 & 0 \\
0 & m-Y_{\dot{v}}-Y_{\dot{r}} \\
0 & -N_{\dot{v}} & I_{z}-N_{\dot{r}}
\end{array}\right], \\
\boldsymbol{D} & =\left[\begin{array}{ccc}
-X_{u} & 0 & 0 \\
0 & -Y_{v}-Y_{r} \\
0 & -N_{v}-N_{r}
\end{array}\right]
\end{aligned}
$$

또한 $\quad \boldsymbol{\nu}=[u, v, r]^{T} \in R^{3 ㄴ ㅡ ㄴ ~ ㅅ ㅓ ㄴ ㅊ ㅔ ㄱ ㅗ ㅈ ㅓ ㅇ ㅈ ㅘ ㅍ ㅛ(B o d y ~ F i x e d ~}$ Frame)에서의 서지, 스웨이 및 요우방향 속도를 나타낸다. 그리고 $\boldsymbol{R}(\varphi)$ 는 선박좌표를 관성좌표로 변환시키는 변환 행렬로 다음 식과 같다.

$$
\boldsymbol{R}(\varphi)=\left[\begin{array}{ccc}
\cos \varphi & -\sin \varphi & 0 \\
\sin \varphi & \cos \varphi & 0 \\
0 & 0 & 1
\end{array}\right]
$$

액추에이터에서 선박에 전달하는 서지, 스웨이 및 요우 방향의 외력 및 모멘트 $\tau_{a}=[X, Y, N] \in R$ 는 다음 식과 같이 주어진다고 한다.

$$
\tau_{a}=\boldsymbol{B}\left(\alpha_{i}\right) \boldsymbol{f}
$$

식 (4)에서 $\boldsymbol{f}=\left[f_{1}, f_{2}, f_{3}, f_{4}\right]^{T} \in F$ 는 4 기의 액추에이 터에 의해 발생되는 제어력을 나타내며, 각 액추에이터가 선박에 접촉하는 위치와 각도를 고려하면 행렬 $\boldsymbol{B}\left(\alpha_{i}\right)$ 는 다음과 같이 나타낼 수 있다.

$$
\boldsymbol{B}\left(\alpha_{i}\right)=\left[\begin{array}{c}
\cos \left(\alpha_{i}\right) \\
\sin \left(\alpha_{i}\right) \\
-l_{i y} \cos \left(\alpha_{i}\right)+l_{i x} \sin \left(\alpha_{i}\right)
\end{array}\right],(i=1, \ldots, 4)
$$

여기서 $l_{i x}, l_{i y}$ 는 선박무게중심점에서 액추에이터 위치 $\left(x_{i}, y_{i}\right)$ 까지의 거리를 각각 나타낸다. 결국 4 기의 액추에 이터를 조합하면 힘과 모멘트 벡터와의 관계는 식 (6)과 같
이 나타낼 수 있다. 여기서 편의상 $s \alpha_{i}=\sin \left(\alpha_{i}\right)$, $c \alpha_{i}=\cos \left(\alpha_{i}\right)$ 로 표현한다.

$$
\tau_{a}=\left[\begin{array}{ccc}
c \alpha_{1} & s \alpha_{1} & -l_{1 y} c \alpha_{1}+l_{1 x} s \alpha_{1} \\
c \alpha_{2} & s \alpha_{2} & -l_{2 y} c \alpha_{2}+l_{2 x} s \alpha_{2} \\
c \alpha_{3} & s \alpha_{3} & -l_{3 y} c \alpha_{3}+l_{3 x} s \alpha_{3} \\
c \alpha_{4} & s \alpha_{4} & -l_{4 y} c \alpha_{4}+l_{4 x} s \alpha_{4}
\end{array}\right]^{T}\left[\begin{array}{c}
f_{1} \\
f_{2} \\
f_{3} \\
f_{4}
\end{array}\right]
$$

제어기 설계에 앞서 그림 4 에 나타낸 각 블록의 전달함 수를 정리하고 블록함수간의 상관관계를 정리한다.

그림 4 에서 전달함수 $G_{T}(s)$ 는 제어력 분배법칙에 이용 되는 변수를 포함한 액추에이터를 나타내며, $G_{V}(s)$ 는 제 어대상인 선박의 전달함수를 나타낸다. 이것을 다음과 같이 상태방정식으로 각각 표현한다.

$$
\begin{gathered}
G_{V} \text { (Vessel) }:\left\{\begin{array}{l}
\dot{x}_{s}=A_{s} x_{s}+B_{s} u_{s} \\
y_{s}=C_{s} x_{s}+D_{s} u_{s}
\end{array}\right. \\
G_{T} \text { (Actuator) }:\left\{\begin{array}{l}
\dot{x}_{t}=A_{t} x_{t}+B_{t} u_{t} \\
y_{t}=C_{t} x_{t}+D_{t} u_{t}
\end{array}\right.
\end{gathered}
$$

여기서 식 (1)의 선박운동방정식으로부터 식 (7)에서 $A_{s}=\boldsymbol{M}^{-1}, B_{s}=-\boldsymbol{M}^{-1} \boldsymbol{D}$ 이고, 상태 $x_{s}=\boldsymbol{\nu}=[u, v, r]$ 로 둔다. 그리고

$$
z=\left[\begin{array}{c}
z_{1} \\
z_{2}
\end{array}\right]=\left[\begin{array}{c}
\tau_{c} \\
\tau_{a}-w
\end{array}\right]
$$

로 정의하면 선박 및 액추에이터 상태방정식 (7)과 (8)에서 의 입력 및 출력벡터는 각각 다음과 같이 나타낼 수 있다.

$$
\begin{aligned}
& \tau_{c}=z_{1} \\
& \tau_{a}=B\left(\alpha_{i}\right) y_{t} \\
& u_{s}=\tau_{a}-w
\end{aligned}
$$

제어기를 설계하기 위해서는 식 (7) 및 식 (8)에서 제어 입력과 제어출력에 대한 정리가 필요하다. 결국 식 (4) (6) 의 표현으로부터, 제어기에서 계산된 제어신호 $\tau_{c}$ 와 액추에 이터에 전달되는 입력 $u_{t}$ 간의 관계는 다음과 같이 다시 정 리할 수 있다.

$$
\tau_{c}=B\left(\alpha_{i}\right) u_{t}
$$

여기서

$$
u_{t}=\left[u_{t 1}, u_{t 2}, u_{t 3}, u_{t 4}\right]^{T}
$$

이다. 그런데 식 (4) (6) 및 식 (11)에서, $B\left(\alpha_{i}\right)$ 가 일반적으 로 정칙이 아니므로 Pseudo-Inverse 기법[1]을 이용하면 식 (11)을 다음과 같이 변환할 수 있다.

$$
u_{t}=B^{*} \tau_{c}
$$

여기서 식 (11)을 식 (12)로 나타낼 수 있기 위해서는 식 (14)가 하나의 해가 된다.

$$
B^{*}=B\left(\alpha_{i}\right)^{T}\left\{B\left(\alpha_{i}\right) B\left(\alpha_{i}\right)^{T}\right\}^{-1}
$$

이것으로부터 액추에이터를 표현한 식 (8)은 strictly 
proper라면 다음과 같이 나타낼 수 있게 된다.

$$
\left\{\begin{array}{l}
\dot{x}_{t}=A_{t} x_{t}+B_{t} B^{*} \tau_{c} \\
y_{t}=C_{t} x_{t}
\end{array}\right.
$$

그리고 제어대상 선박에 대한 상태방정식 (7)은 $u_{s}=\tau_{a}-w$ 인 관계로부터 다음 과 같이 표현할 수 있다.

$$
\left\{\begin{array}{l}
\dot{x}_{s}=A_{s} x_{s}+B_{s} B\left(\alpha_{i}\right) C_{t} x_{t}-B_{s} w \\
y_{s}=C_{s} x_{s}+D_{s} B\left(\alpha_{i}\right) C_{t} x_{t}-D_{s} w
\end{array}\right.
$$

이상으로부터 제어신호, 제어신호 전달행렬 및 제어대상 간의 연결관계를 정리하는 것이 완료되었다. 이것을 기초로 강인제어기법에 따라 주어진 설계사양을 만족하는 제어기를 설계하기 위해 식 (17)과 같이 일반화 플랜트를 구성한다.

$$
\left[\begin{array}{l}
\dot{\eta}_{p} \\
\dot{x}_{s} \\
\dot{x}_{t} \\
z_{1} \\
z_{2} \\
y_{s}
\end{array}\right]=\left[\begin{array}{ccccc}
0 & I & 0 & 0 & 0 \\
0 & A_{s} & B_{s} B\left(\alpha_{i}\right) C_{t} & -B_{s} & 0 \\
0 & 0 & A_{t} & 0 & B_{t} B^{*} \\
0 & 0 & 0 & 0 & I \\
0 & 0 & B\left(\alpha_{i}\right) C_{t} & -I & 0 \\
I & 0 & 0 & 0 & 0
\end{array}\right]\left[\begin{array}{c}
\eta_{p} \\
x_{s} \\
x_{t} \\
w \\
\tau_{c}
\end{array}\right]
$$

위 식을 간략하게 다시 정리하면 다음 식과 같이 표현할 수 있다.

$$
\left[\begin{array}{c}
\dot{x} \\
z \\
y
\end{array}\right]=\left[\begin{array}{ccc}
A & B_{1} & B_{2} \\
C_{1} & D_{11} & D_{12} \\
C_{2} & D_{21} & 0
\end{array}\right]\left[\begin{array}{l}
x \\
w \\
u
\end{array}\right]
$$

여기서 $x=\left[\eta^{T}, x_{s}^{T}, x_{t}^{T}\right]^{T}, z=\left[z_{1}^{T}, z_{2}^{T}\right]^{T} y=y_{s}$ 이다. 그 리고 식 (17)로부터 식 (18)의 각 요소행렬은 다음과 같이 주어진다.

$$
\begin{aligned}
& A=\left[\begin{array}{ccc}
0 & I & 0 \\
0 & A_{s} & B_{s} B\left(\alpha_{i}\right) C_{t} \\
0 & 0 & A_{t}
\end{array}\right], B_{1}=\left[\begin{array}{c}
0 \\
-B_{s} \\
0
\end{array}\right], B_{2}=\left[\begin{array}{c}
0 \\
0 \\
B_{t} B^{*}
\end{array}\right], \\
& C_{1}=\left[\begin{array}{ccc}
0 & 0 & 0 \\
0 & 0 & B\left(\alpha_{i}\right) C_{t}
\end{array}\right], C_{2}=\left[\begin{array}{lll}
I & 0 & 0
\end{array}\right] \\
& D_{11}=\left[\begin{array}{c}
0 \\
-I
\end{array}\right], D_{12}=\left[\begin{array}{l}
I \\
0
\end{array}\right], D_{21}=D_{22}=0
\end{aligned}
$$

앞서 기술하였듯이 제어력 분배 문제에 대한 설계지표는 $\left\|\tau_{c}-\tau_{a}\left(\boldsymbol{f}_{i}, \alpha_{i}\right)\right\|<\gamma(>0)$ 와 같이 주어질 수 있으므로, 강인제어기법에 따른 그림 3 및 그림 4의 표현법을 이용하 면 이 문제는 외란 등의 영향을 최소화하는 문제로 정리할 수 있게 된다. 따라서 본 논문에서는 $H_{2} / H_{\infty}$ 설계사양을 만족하는 제어기를 설계하도록 한다. 즉, 그 설계지표를 다 음 식과 같이 정의한다.

$$
\left\|T_{z w}(s)\right\|_{\infty}+\left\|T_{y_{s} w}(s)\right\|_{2}<\gamma
$$

여기서 $T_{z w}(s)$ 는 외란 $w$ 에서 $z=\left[z_{1}^{T}, z_{2}^{T}\right]^{T}$ 까지의 전달 함수, $T_{y_{s} w}(s)$ 는 외란 $w$ 에서 제어출력 $y_{s}$ 까지의 전달함수 를 각각 나타낸다. $H_{2} / H_{\infty}$ 설계법은 외란의 영항을 최소화 하면서 제어성능까지 동시에 달성하고자 할 때 도입하는 설계기법이다. 이것을 LMI 기법으로 기술하면 다음의 부등
식을 동시에 만족하는 해를 구하는 것으로 정리된다.

먼저 $H_{\infty}$ 제어성능을 달성하기 위해서는 아래 부등식 (21)을 만족하는 정정(positive definite)해 $X_{\infty}$ (>0)를 구하 면 된다[8-10].

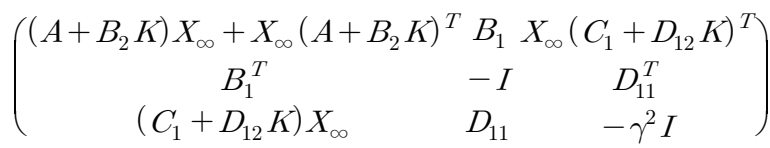

그리고 $H_{2}$ 제어성능을 달성하기 위해서는 아래 부등식 (22) (24)를 동시에 만족하는 두 개의 대칭행렬 $X_{2}, Q$ 가 존재함을 보이면 된다.

$$
\begin{gathered}
\left(\begin{array}{cc}
\left(A+B_{2} K\right) X_{2}+X_{2}\left(A+B_{2} K\right)^{T} & B_{1} \\
B_{1}^{T} & -I
\end{array}\right)<0 \\
\left.Q \quad \begin{array}{cc}
\left(C_{2}+D_{22} K\right) X_{2} \\
X_{2}\left(C_{2}+D_{22} K\right)^{T} & X_{2}
\end{array}\right)>0 \\
\operatorname{Trace}(Q)<\nu^{2}(>0)
\end{gathered}
$$

위 부등식에서 $X: X_{\infty}=X_{2}$ 및 $Y:=K X$ 라 두면, 결 국 $H_{2} / H_{\infty}$ 설계지표를 만족하는 제어기는 다음의 부등식을 동시에 만족하는 해 $X, Y, Q$ 를 구하는 것으로 정의된다.

$$
\begin{aligned}
& \left(\begin{array}{ccc}
A X+X A^{T}+B_{2} Y+Y^{T} B_{2}^{T} & B_{1} & X C_{1}^{T}+Y^{T} D_{12}^{T} \\
B_{1}^{T} & -I & D_{11}^{T} \\
C_{1} X+D_{12} Y & D_{11} & -\gamma^{2} I
\end{array}\right)<0 \\
& \left(\begin{array}{cc}
Q & C_{2} X+D_{22} Y \\
X C_{2}^{T}+Y^{T} D_{22}^{T} & X
\end{array}\right)>0 \\
& \operatorname{Trace}(Q)<\nu^{2}(>0)
\end{aligned}
$$

\section{IV. 시뮬레이션}

III 장에 기술한 내용을 기초로 제어대상 선박을 선정하 고 선박운동제어를 위한 제어기를 설계한 후 시뮬레이션을 수행한다. 본 논문에서는 4 기의 액추에이터가 설치된 선박 모델을 제어대상으로 한다. 이때 선박과 액추에이터를 나타 낸 식 (7)과 식 (8)에서 각 행렬은 식 (28) 및 식 (29)와 같 다[4].

$$
\begin{aligned}
A_{s} & =\left[\begin{array}{ccc}
-0.2105 & 0 & 0 \\
0 & A_{\delta_{1}} & A_{\delta_{2}} \\
0 & A_{\delta_{3}} & A_{\delta_{4}}
\end{array}\right] \\
B_{s} & =\left[\begin{array}{ccc}
0.0526 & 0 & 0 \\
0 & 0.0288 & 0.0206 \\
0 & 0.0206 & 1.0351
\end{array}\right] \\
C_{s} & =[\boldsymbol{I}], D_{s}=[\mathbf{0}] \\
A_{t} & =\operatorname{diag}[-2.5,-2.5,-2.5,-2.5] \\
B_{t} & =[\boldsymbol{I}] \\
C_{t} & =[\boldsymbol{I}] \times 1.5 \\
D_{t} & =[\mathbf{0}]
\end{aligned}
$$

식 (28)의 행렬 $A_{s}$ 에서 $A_{\delta_{i}}(i=1, \ldots, 4)$ 는 변동하는 파라 미터를 나타내며 공칭값(nominal value)은 각각 다음과 같이 
주어진다.

$$
\begin{array}{ll}
A_{\delta_{1}}=-0.1729, & A_{\delta_{2}}=-0.0206, \\
A_{\delta_{3}}=-0.1235, & A_{\delta_{4}}=-1.0351
\end{array}
$$

여기서 선박에 설치되는 각 액추에이터의 위치는 다음과 같다[4].

$$
\begin{aligned}
& \left(x_{1}, y_{1}\right)=(0.5,-0.2), \quad\left(x_{2}, y_{2}\right)=(-0.5,-0.2) \\
& \left(x_{3}, y_{3}\right)=(-0.5,0.2), \quad\left(x_{4}, y_{4}\right)=(0.5,0.2)
\end{aligned}
$$

그리고 액추에이터로부터 만들어지는 제어력이 선체에 작 용하는 각도 $\alpha_{i}(i=1, \ldots, 4)$ 는 다음과 같이 설정하였다.

$$
\begin{aligned}
& \pi / 2 \leq \alpha_{1} \leq 5 \pi / 6, \pi / 6 \leq \alpha_{2} \leq \pi / 2, \\
& -\pi / 2 \leq \alpha_{3} \leq-\pi / 6, \quad-5 \pi / 6 \leq \alpha_{4} \leq-\pi / 2,
\end{aligned}
$$

특히 본 논문에서는 불확실성에 강인한 제어계를 구축하 기 위해 선박의 물리특성이 일정범위에서 변한다고 가정한 다. 선박의 주행속도, 적재량변동 및 환경변화에 따라 그 물리특성이 변한다는 것을 고려한 것이다. 그래서 식 (28) 에서 변동하는 파라미터의 크기는 식 (30)에 주어진 공칭값 의 $30 \%$ 범위내에서 변한다고 가정한다. 즉,

$$
\begin{aligned}
& -0.2248 \leq A_{\delta_{1}}(-0.1729) \leq-0.1210 \\
& -0.0268 \leq A_{\delta_{2}}(-0.0206) \leq-0.0144 \\
& -0.1606 \leq A_{\delta_{3}}(-0.1235) \leq-0.0865 \\
& -1.3456 \leq A_{\delta_{4}}(-1.0351) \leq-0.7246
\end{aligned}
$$

와 같이 정의하면 불확실성을 포함한 식 (28)의 행렬 $A_{s}$ 는 다음과 같이 나타낼 수 있다[8,9].

$$
\begin{aligned}
& A_{s}(\delta)=\sum_{j=1}^{k} \kappa_{j} A_{s j} \\
& \sum_{j=1}^{k} \kappa_{j}=1, \kappa \geq 0
\end{aligned}
$$

여기서 $A_{s j}$ 는 단점행렬(vertex)을 나타낸다.

이와 같은 조건아래 제어계 설계사양을 만족하는 제어기 를 구하기 위해서는 식 (19)의 $A_{s}$ 를 식 (33)의 $A_{s}(\delta)$ 로 치 환한 후, 부등식 (25) (27)을 동시에 만족하는 $X, Y, Q$ 를 구하면 된다.

이것으로부터 LMI Matlab Tool [10]을 이용하여 $H_{2} / H_{\infty}$ 설계사양을 만족하는 제어기 $K=Y X^{-1}$ 를 다음과 같이 구 하였다.

$$
\begin{aligned}
& K=\left[\begin{array}{ccccc}
-1.1982 & -0.0002 & -0.0001 & -2.7945 & -0.0017 \\
-0.0004 & -1.1298 & -0.4399 & -0.0009 & -10.3517 \\
0.0008 & 11.2250 & -8.9813 & 0.0029 & 113.7789
\end{array}\right. \\
& \begin{array}{llllll}
0.0002 & 0.0464 & -0.0465 & -0.0464 & 0.0464
\end{array} \\
& \left.\begin{array}{ccccc}
1.4020 & 0.0054 & -0.1889 & 0.3184 & -0.1350 \\
-41.3252 & -2.4167 & 3.9094 & -8.1266 & 6.6340
\end{array}\right]
\end{aligned}
$$

시뮬레이션 결과를 그림 5 그림 7에 나타내었다. 시뮬레 이션 기본 조건은 선박이 원래 정지위치로부터 이탈해 있 다고 가정하고, 이상태로부터 원래의 위치로 되돌리는 문제 를 고려한다. 즉, 선박위치좌표 $(x, y, \psi)$ 가 원점 $(0,0,0)$ 에서 $(0.5,-0.5,0.2)$ 로 이동한 상태에 있다고 간주하고,
제어력으로 선박을 원점 $(0,0,0)$ 으로 복귀시키는 시뮬레이 션을 수행하였다. 여기서 식 (33)과 같은 파라미터 변동을 고려하여 공칭값을 갖는 경우를 포함하여 9 가지의 시뮬레 이션 조건을 구성하였다. 그래서 그림 5 그림 7과 같이 시 뮬레이션 결과를 얻을 수 있었다. 즉, 식 (33)과 같이 변동 하는 파라미터가 최솟값 및 최댓값을 갖는 모든 경우에 대 한 시뮬레이션 결과이다. 그림 5 는 서지방향 위치, 그림 6 은 스웨이방향 위치를 나타내며, 그림 7은 요우각을 나타낸 다. 다수의 파라미터가 변동하는 조건에도 불구하고 제어대 상 선박을 오차없이 원래 위치로 복귀시키고 있음을 확인 할 수 있다.

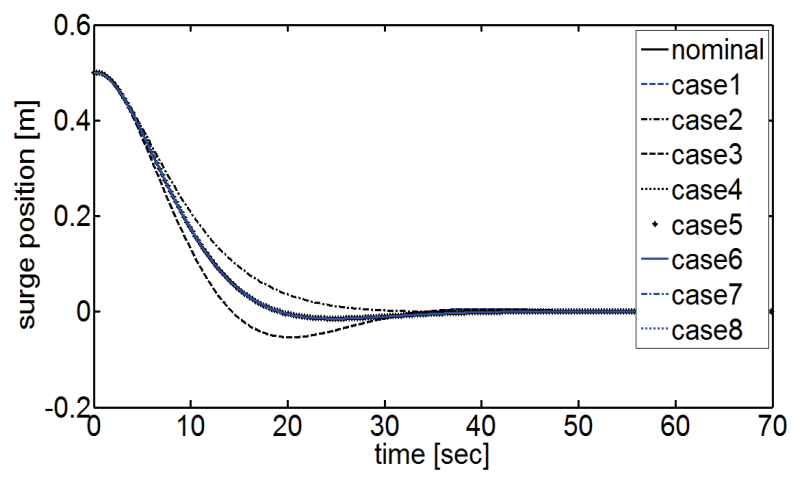

그림 5. Initial 응답 : 서지방향 위치 [m].

Fig. 5. Initial response : surge position [m].

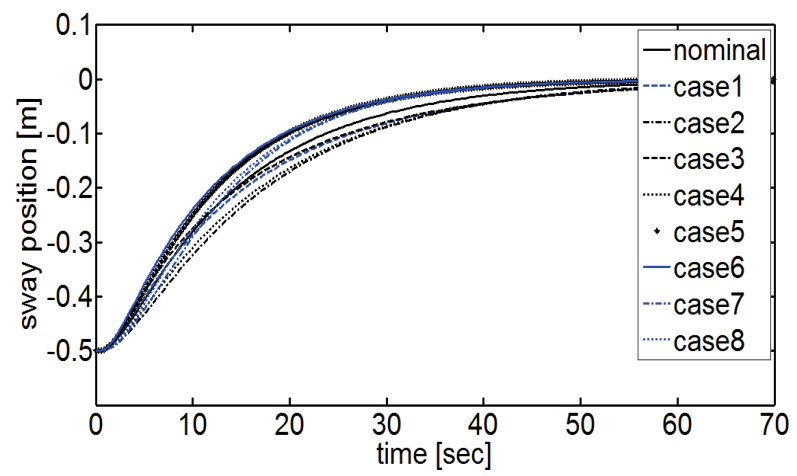

그림 6. Initial 응답: 스웨이방향 위치 [m].

Fig. 6. Initial response : sway position [m].

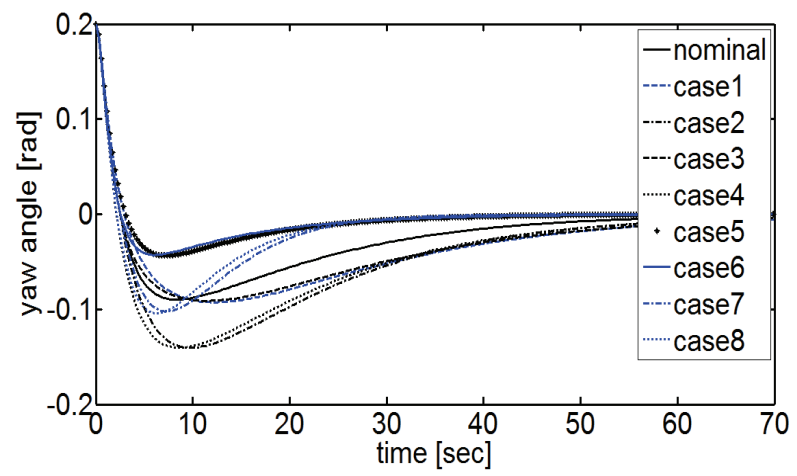

그림 7. Initial 응답: 요우 각 [rad].

Fig. 7. Initial response : yaw angle [rad]. 

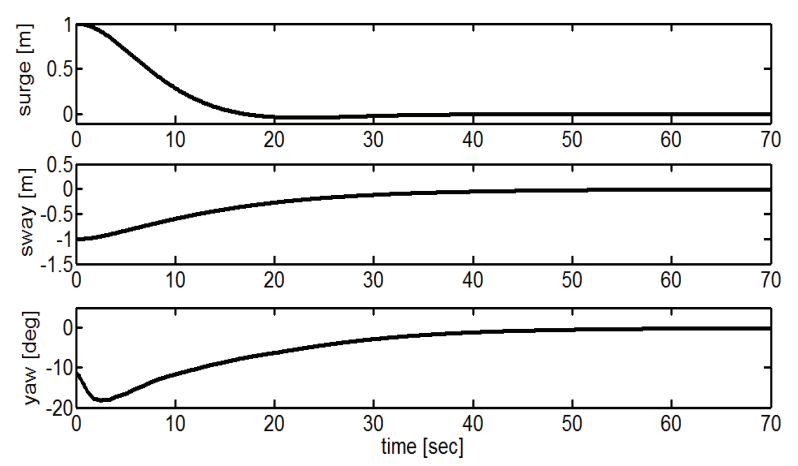

그림 8. Initial 응답. 공칭계의 서지, 스웨이, 요우각.

Fig. 8. Initial responses of nominal system.
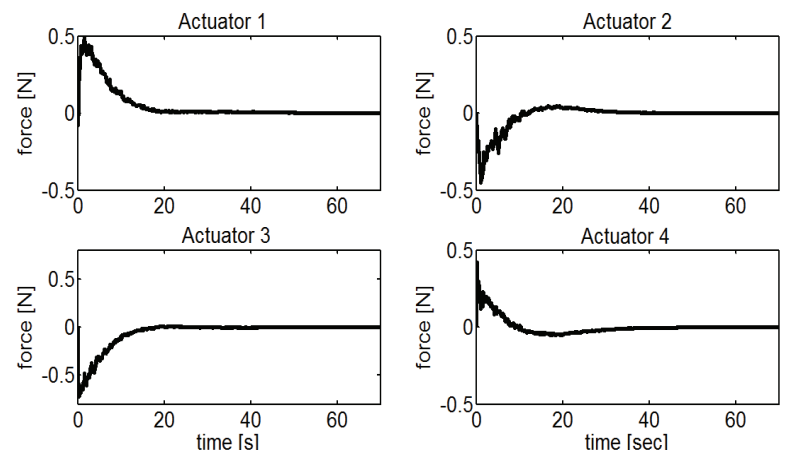

그림 9. 액추에이터 추진력.

Fig. 9. Thrusts made by four actuators.
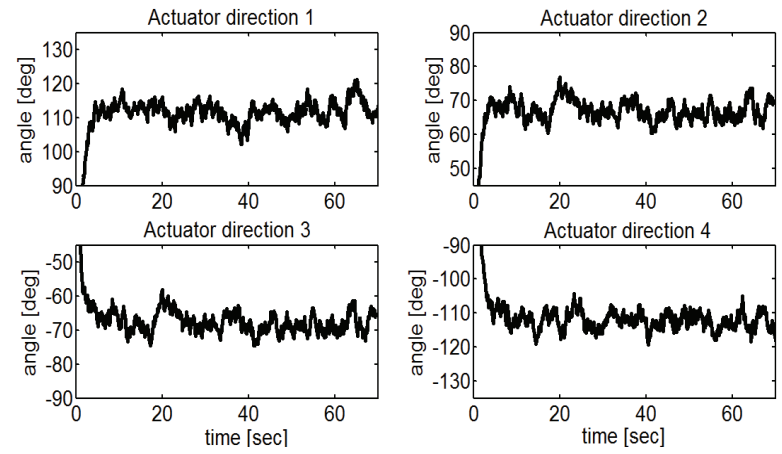

그림 10 . 액추에이터 회전각도.

Fig. 10. Actuator moving angles.

그리고 그림 8 그림 10 은 선박에 설치된 4개의 액추에이 터 운동특성을 나타내고 있다. 액추에이터는 최대 $0.7[\mathrm{~N}]$ 정 도의 추진력을 발생할 수 있도록 설계되어 있다. 공칭계를 대상으로 그림 8과 같이 어떤 임의의 초기상태에서 평형상 태로 복귀시키는 경우의 시뮬레이션을 수행하였다. 이때 양 호한 응답(그림 8)과 액추에이터 발생추력한계를 모두 만족 시키고 있음을 그림 9로부터 확인할 수 있다. 또한 그림 10 은 이때의 액추에이터 회전상태를 나타내고 있다. 이것 또 한 식 (32)에 주어진 각도 제약조건을 만족시키고 있다.

\section{V. 결론}

본 논문에서는 제어기로부터 계산된 제어신호를 액추에
이터 및 제어대상으로 분배하는 제어력 분배 문제에 대해 고찰하였다. 제어력을 적절히 분배하기 위한 많은 연구결과 가 이미 보고되어 있으나 그 대부분이 제어기를 먼저 설계 하여 두고 이와는 별도로 독립적인 과정을 거쳐 제어력 분 배를 위한 전달행렬을 구하는 것이다. 기존의 연구결과가 다소 간단하다 할 수 있으나 제어기설계와 제어력 분배를 별도로 다루다 보니 제어력 분배과정이후의 전체 제어계의 안정성해석 및 제어성능평가가 수행되지 않는 문제가 발생 한다. 따라서 본 논문에서는 제어력 분배 문제를 강인제어 기법으로 변환하여 다루는 새로운 방법을 제안하였고, 안정 성 및 제어성능에 관한 조건 등을 동시에 만족시킬 수 있 는 결과를 도출하였다. 즉, $H_{2} / H_{\infty}$ 제어성능을 달성하기 위 한 설계사양을 설정하고, 다수의 파라미터가 변동하는 경우 에도 제어계 안정성과 제어성능을 달성할 수 있는 제어계 설계방법을 제시하였다.

이것은 기존의 설계기법과는 달리 두 가지 문제를 통합 적 관점에서 해결할 수 있는 새로운 방법이며, 시률레이션 을 통해 제안한 기법의 유효성을 검증하였다.

\section{REFERENCES}

[1] O. J. Sordalen, "Optimal thrust allocation for marine vessels," Control Engineering Practice, vol. 5, no. 9, pp. 1223-1231, 1997.

[2] J. P. Strand, "Nonlinear position control system design for marine vessels," Ph.D. Thesis, Dept of Engineering Cybernetics, Norwegian University of Science and Technology, 1999.

[3] T. I. Fossen and S. P. Berge, "Nonlinear vectorial backstepping design for global exponential tracking of marine vessels in the presence of actuator dynamics," Proc. of 36th Conference on Decision and Control, pp. 4237-4242, 1999.

[4] T. I. Fossen, Marine Control System Guidance, Navigation, Rigs and Underwater Vehicle, Trondheim, Norway, Norwegian University of Science and Technology, 2002.

[5] M. Bodson, "Evaluation of optimization methods for control allocation," Journal of Guidance, Control, and Dynamics, vol. 25, no. 4, pp. 703-711, 2002.

[6] V. P. Bui and Y. B. Kim, "Development of constrained control allocation for ship berthing by using autonomous tugboats," International Journal of Control, Automation, and Systems, vol. 9, no. 6, pp. 1203-1208, 2011.

[7] V. P. Bui and Y. B. Kim, "Design of sliding mode controller for ship position control," Journal of Institute of Control, Robotics and Systems (in Korean), vol. 17, no. 9, pp. 869-874, 2011.

[8] P. Gahinet, "Explicit controller formulas for LMI-based $H_{\infty}$ synthesis," Proc. of American Control Conference, pp. 2396-2400, 1994. 
[9] P. Gahinet and P. Apkarian, "A linear matrix inequality approach to $H_{\infty}$ control," International Journal of Robust and Nonlinear Control, pp. 421-448, 1994.

[10] P. Gahinet, A. Nemirovski, A. J. Laub, and M. Chilali, LMI Control Toolbox, Math Works Inc, 1995.

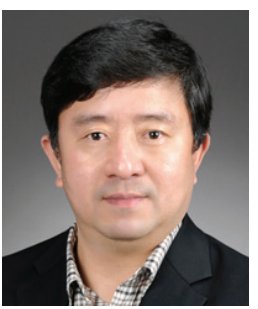

\section{강 창 남}

1984년 제주대학교 기계공학과 졸업. 1987년 부경대학교 대학원 석사. 1997 년 한국해양대 대학원 박사. 1990년 현재 제주대학교 공과대학 기계시스템 공학부 교수. 관심분야는 선박운동해 석 및 제어.

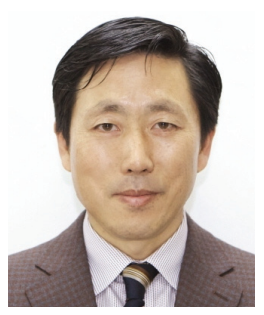

\section{김 영 복}

1989년 부경대학교 기계시스템공학과 졸업. 1991년 동 대학원 석사. 1996년 KOBE 대학 대학원 박사. 2001년 2002 년 군산대학교 전임강사. 2002년 현재 부경대학교 기계시스템공학과 교수. IEEE Senior Member. ICROS/ASME/ $\mathrm{KSME} / \mathrm{SICE}$ 정회원. 관심분야는 항만장비자동화, 수상운동 체 운동해석 및 제어시스템 구축. 